\title{
Study of ancient mortars from Sagalassos (Turkey) in view of their conservation
}

\author{
P. Degryse ${ }^{\mathrm{a}, *}$, J. Elsen $^{\mathrm{a}}$, M. Waelkens ${ }^{\mathrm{b}}$ \\ ${ }^{a}$ Afdeling Fysico-chemische Geologie, Katholieke Universiteit Leuven, Celestijnenlaan 200C, B-3001 Louvain, Belgium \\ ${ }^{\mathrm{b}}$ Afdeling Archeologie, Katholieke Universiteit Leuven, Maria Theresiastraat 21, B-3000 Louvain, Belgium
}

Received 13 August 2001; accepted 3 April 2002

\begin{abstract}
Since 1990, regular archeological excavations are done in the Roman city of Sagalassos (southwestern Turkey) by the Catholic University of Leuven (Belgium). The mineralogy and petrography of the lime mortars at Sagalassos have been studied in detail as part of an investigation of the provenance of mineral raw materials present in the territory of Sagalassos. The samples were analysed with optical microscopy on thin sections followed by XRD analyses to design a suitable repair mortar. The lime used as binder was burnt from local Triassic limestones and prepared by dry slaking. Three main types of aggregates have been identified: limestone from local Mesozoic limestones, crushed ceramics from locally produced coarse wares and volcanic tuff from a nearby volcanic region. To preserve the excavated remains in very harsh climatic winter conditions, experimental mixtures of restoration mortar have been tested for strength and frost resistance using similar raw materials as in ancient times. The proposed mortar for further on-site conservation and restoration consists of a mix of lime with crushed volcanic rock from the region of Isparta. This composition is very similar to the original Roman material and shows a high frost resistance in freeze-thaw testing. (C) 2002 Elsevier Science Ltd. All rights reserved.
\end{abstract}

Keywords: Freezing and thawing; Pozzolan; Mortar; Conservation

\section{Introduction}

For more than a decade, regular archeological excavations directed by M. Waelkens have been carried out in the city of Sagalassos by the Catholic University of Leuven (Belgium). The city of Sagalassos is situated in southwestern Asia Minor, in the region of Pisidia, at an altitude between 1300 and $1600 \mathrm{~m}$, in the western Taurus mountain range (Fig. 1). The site may have been temporarily occupied in the Neolithic Period, but it must have been settled during the middle Bronze Age at the latest. During the Hellenistic period, it rose in importance, and in Roman Imperial times, it became the wealthiest city of Pisidia [1].

After a systematic survey of the city and its mapping, the enormous scientific potential of the virtually untouched site became clear, and it was decided to carry out a more interdisciplinary research approach involving a systematic study of the whole territory of classical Sagalassos, invol-

\footnotetext{
* Corresponding author. Tel.: +32-16-327797; fax: +32-16-327981

E-mail address: patrick.degryse@geo.kuleuven.ac.be (P. Degryse).
}

ving amongst others geologists, geomorphologists, palaeobotanists and archeozoologists. One of the research topics of this interdisciplinary approach is a broad investigation of the provenance of mineral raw materials present in the territory of Sagalassos, linked to manmade structures and artefacts found in the city: clays and ceramics, building stones, mortars, plasters, glass and metals [2].

The frost regime at Sagalassos is high with high amounts of rainfall ( $885 \mathrm{~mm} /$ year $)$, long periods of frost (7 months) and a very high number of freeze-thaw cycles ( 100 cycles or more/year). Preserving the excavated remains in such harsh conditions as those prevailing at Sagalassos during the winter months has become one of the major concerns of the excavations. Especially for brick constructions and rubble walls (walls constructed with mortar and large natural stone pebbles), which gradually replaced stone constructions during Roman Imperial times, this problem has become very important. Moreover, many of these surfaces were not originally exposed, since they were either inner walls or plastered or covered by marble veneer. As a result, most of these mortars had already disintegrated as the result of wet burial circumstances or weathered rapidly as the result of 


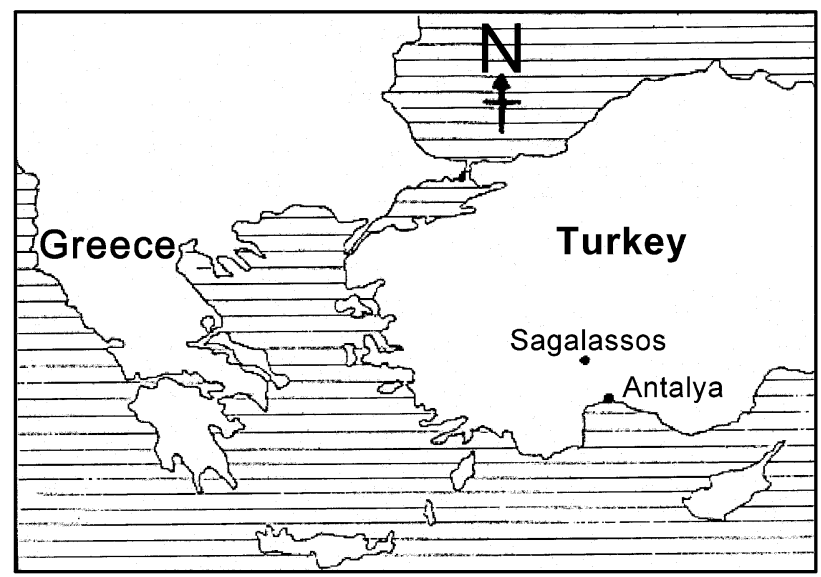

Fig. 1. The location of Sagalassos in modern Turkey, $\pm 120 \mathrm{~km}$ from Antalya.

their quick exposure in the excavation. Especially the ancient bedding mortars used for the Roman Baths at Sagalassos are highly deteriorated. The bonding with the bricks is so poor that mortar pieces can be detached easily by hand. Some earlier attempts to repair these mortars proved to be unsuccessful, showing rapid deterioration with cracks in the mortar parallel to the bricks, characteristic for frost damage. Therefore, the need for a frost-resistant mortar mixture to repair damaged structures and to prevent damage to structures exposed in the excavation became an urgent matter.

During the whole 20th century in Western Europe and even more pronounced in Belgium, there has been a gradual replacement of lime mortars for masonry structures by cement based mortars, also for restoration purposes. However, there is a general agreement that the use of highly hydraulic cement-based mortars for restoration purposes has resulted in extensive damage to cultural heritage, because of the incompatibility of these mortars with the ancient materials $[3,4]$. These damage cases, together with the principle of 'authenticity', defined in the ICOMOS Venice Charter 203 [5] in 1964 and further refined in the ICOMOS 'Nara Document' [6] in 1994, resulted from 1980 on in a renewed interest regarding the use of (hydraulic) lime mortars in the field of restoration. However, traditional know-how and experience in the preparation and the application of lime mortars have almost been lost, and this has led to a number of unsuccessful restoration works in the last decades. Analyses of these damage cases for a number of recent mortar repairs has resulted in an increased awareness of the importance of the compatibility between the new repair mortar and the old material [7] and, accordingly, between the repointing mortar and the old bedding mortar [8].

A mineralogical and petrographical study of the ancient mortars from Sagalassos was undertaken to find out the provenance of the mineral raw materials and to determine the composition and properties of these ancient mortars with a view to the formulation of the composition of an appro- priate repair mortar. An experimental study was carried out to design a suitable mortar for restoration and conservation purposes with the durability against frost resistance as one of the central issues.

\section{Materials and methods}

The presence of lumps of mineral matter in the mortar produces a heterogeneous consistency, and in order to obtain a representative sample, the samples were cut into two halves, and sections about $8 \mathrm{~mm}$ thick were taken from one half. One section was ground and used for XRD analysis to identify mineral constituents. A second slice was used for the preparation of a thin section. Because of their porous and friable nature, prior to being examined under a conventional polarising microscope, the samples were impregnated in vacuum with a resin dyed blue. The mineralogical phases and the porosity of a selection of samples were quantified by image analysis on thin sections.

\section{Results}

\subsection{Characterisation of the Sagalassos mortars}

At Sagalassos, lime mortars with different types of aggregates were used. A great number of mortar samples used for different building purposes and dating from the late-Hellenistic to the early-Byzantine period were collected for analysis. With respect to their function, the samples can be divided into two main groups. The first group consists of mortars used in architectural structures and tombs from the beginning of the Imperial period to the 6th-early 7 th century AD. This group includes materials used to bind building blocks (mostly bricks and limestones), mortars used as rendering or coating on walls before the application of plaster and mortars from fills and foundations. The second group consists of materials used in various waterrelated structures and includes mortars from casings of water conduits, jointing compounds from terracotta pipes and mortars used in the lining and coating of reservoirs and aqueducts. Three types of aggregates were recognised: limestone, crushed ceramics and volcanic tuff and lava. Sand and marble powder, commonly used in the Greek and Roman world, were not found in the Sagalassos mortar. A remark has to be made that here, 'sand' is used as indicated in Roman texts by Vitruvius (De architectura II, 4-5): either 'quarry sand' or 'river or sea sand' which in practice means quartz sand. The aforementioned aggregates must have been replaced by limestone at Sagalassos, since neither river, sea or quarry (quartz) sand nor marble is present on the territory.

The first type of aggregate is a pure limestone (Fig. 2), which originated, as the lime itself, from the local limestones of the Lycian nappes, omnipresent in the vicinity of 


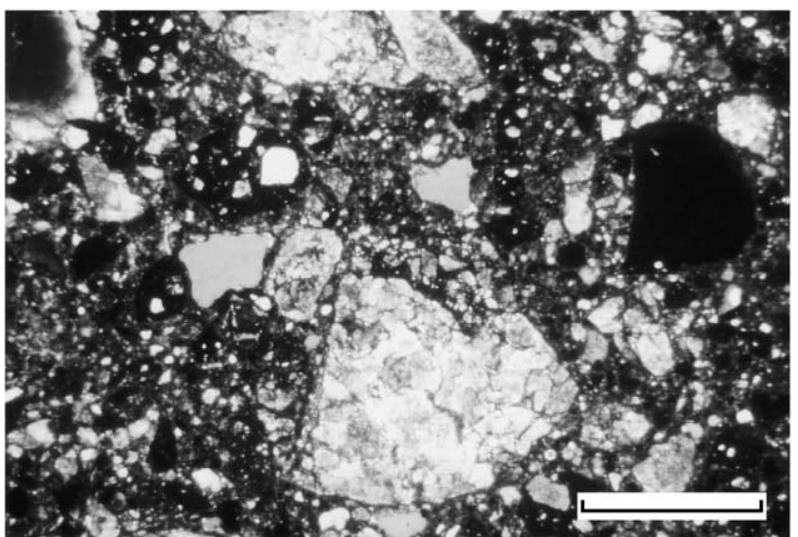

Fig. 2. Microphotograph of limestone aggregates in the Roman lime mortar, scale bar is $250 \mu \mathrm{m}$, crossed polaroids.

the city and composed of Mesozoic to early Tertiary marine sediments. The limestone aggregate fragments show the same characteristics as the limestones identified in the building stones of Sagalassos [9]. The limestone around Sagalassos is rather pure, and it is logical that the inhabitants of the Roman period should have chosen it as a raw material [10]. Because lime lumps can be found in the mortars, dry slaking is assumed [11]. Dry slaking is the technique in which lime $(\mathrm{CaO})$ is combined with the minimum amount of water necessary to alter all lime present into portlandite $\left(\mathrm{Ca}(\mathrm{OH})_{2}\right)$. It is opposed to the technique of wet slaking, in which an excess of water is used [11].

Crushed ceramics as an aggregate (Fig. 3) are found from early Hellenistic to early Byzantine times in mortars related to water-bearing constructions. Samples taken in a context of water-related constructions containing no ceramics belong to load-bearing parts of the construction or surround terracotta water pipes, keeping the pipes in place rather than making the construction watertight. At Sagalassos, crushed ceramics also occur in mortars not directly related to water-

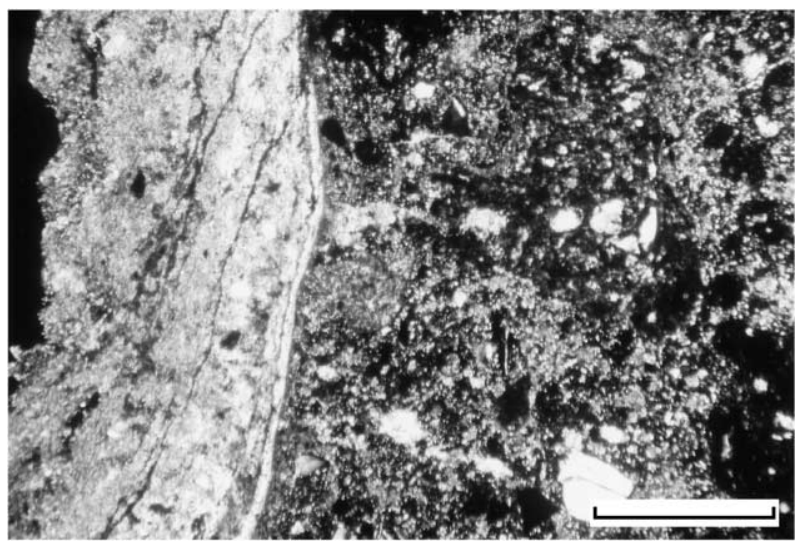

Fig. 3. Microphotograph of ceramic aggregates in the Roman lime mortar, scale bar is $250 \mu \mathrm{m}$, crossed polaroids. bearing constructions but, for example, to protect the inside of the wall from moisture.

The third type of aggregate used at Sagalassos consists of volcanic material (Fig. 4), which was added to mortars by both Greeks and Romans to improve their quality, as it was noticed that this improved the hardness of the mixture and produced mortars that harden even underwater (Vitruvius, De architectura II, 4-5, VII, 4 and VIII, 6 and 14). Mortars with volcanic aggregates were used for construction purposes where higher compressive strength was necessary, for instance, in the masonry of the Roman Baths in Sagalassos. Petrographically, the aggregates in these mortars are very similar to volcanic deposits from the region of Gölçük, NW of Sagalassos. Both lava and pumice fragments and zoned augites and plagioclases are observed in the mortars as in the rocks from the volcanic region. The fragments in the mortars often have broken rims, indicating that the hard tuff and lava layers have been crushed. Samples from the volcanic deposits of the Gölçük region, mainly consisting of tuff layers, observed as cliffs and as loose sandy material, were collected for a more detailed study. The tuffs have a light-coloured matrix with many inclusions such as pumice, lava fragments and mineral grains. The lava layers have a grey, fine-grained matrix with phenocrysts of pyroxenes and biotites. Diopside and amphiboles are present in small amounts. Petrographically, the volcanic rocks consist of a cumulate of submicroscopic crystals and a glass phase (the matrix), with inclusions of varying size, from rock to monocrystalline fragments. The rock fragments consist of pumice, lava and sporadically sandstone. Plagioclases, alkali-feldspars, augites, diopsides, biotites and amphiboles occur as individual crystals. The crystals are strongly zoned. The matrix consists mainly of sanidine and anorthite crystals (determined by XRD) and an amorphous glass phase. The matrix is more important in the fine-grained tuff. The volcanic rocks of the area studied can thus be identified as aggregates in the mortars of Sagalassos.

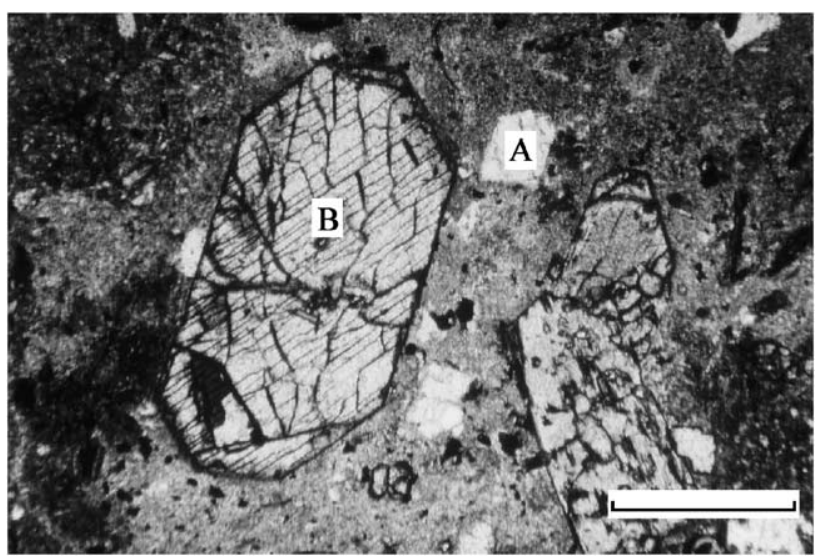

Fig. 4. Microphotograph of volcanic aggregates in the Roman lime mortar [feldspar (A) and augite (B) as mineral constituents, together with and a glass phase], scale bar is $250 \mu \mathrm{m}$, crossed polaroids. 
Table 1

Composition and measurement results of experimental mortar test objects

\begin{tabular}{|c|c|c|c|c|c|c|c|}
\hline Sample & $\begin{array}{l}\text { Lime } \\
(\mathrm{g})\end{array}$ & $\begin{array}{l}\text { Ceramics } \\
(\mathrm{g})\end{array}$ & $\begin{array}{l}\text { Volcanics } \\
(\mathrm{g})\end{array}$ & $\begin{array}{l}\text { Water } \\
(\mathrm{g})\end{array}$ & $\begin{array}{l}\text { E-modulus after } \\
28 \text { days }(\mathrm{GPa})\end{array}$ & $\begin{array}{l}\text { E-modulus decrease (\%) } \\
\text { RUN 1/RUN } 1+2\end{array}$ & $\begin{array}{l}\text { Number of freezing - thawing } \\
\text { cycles before destruction }\end{array}$ \\
\hline VO-1 & 48 & 0 & 59 & 10 & 3.6 & $0 / 25$ & no visual damage \\
\hline VO-2 & 48 & 0 & 59 & 10 & 3.1 & $26 / 100$ & 7 \\
\hline VO-3 & 48 & 0 & 59 & 10 & 2.7 & $0 / 33$ & no visual damage \\
\hline CE-1 & 75 & 40 & 0 & 0 & 1.9 & $100 / 100$ & 3 \\
\hline CE-2 & 75 & 40 & 0 & 0 & 2.1 & $100 / 100$ & 3 \\
\hline VO-3/CE-1 & 80 & 80 & 40 & 18 & 3.4 & $100 / 100$ & 5 \\
\hline VO-3/CE-2 & 80 & 80 & 40 & 18 & 3.0 & $100 / 100$ & 4 \\
\hline VO-3/LI-1 & 80 & 0 & 97 & 25 & 2.9 & $41 / 100$ & 7 \\
\hline VO-3/CE-1/LI-1 & 80 & 80 & 40 & 25 & 3.9 & $100 / 100$ & 5 \\
\hline VO-3/LI-2 & 23 & 0 & 28 & 8 & 3.6 & $12 / 100$ & 9 \\
\hline
\end{tabular}

VO-1: consolidated volcanic tuff from the Tras quarry in Isparta, lower layer, lacking inclusions.

VO-2: consolidated volcanic tuff from the Tras quarry in Isparta, upper layer, pumice and lava inclusions.

VO-3: consolidated tuff from building stones used on the site of Sagalassos (origin around lake Gölçük).

CE-1: prepared by crushing samples of building ceramics of the site of Sagalassos, bricks of the Roman baths.

CE-2: prepared by crushing samples of cooking ware and storage vessels of the site of Sagalassos.

LI-1: prepared by crushing limestone from the Lycian nappes north of Sagalassos.

LI-2: limestone fragments prepared from original Roman mortar samples from the site of Sagalassos.

RUN 1-six cycles: high frost $\left(-15^{\circ} \mathrm{C}\right)$ regime, medium water content $(12 \mathrm{~h}$ under water).

RUN 2-six cycles: high frost $\left(-15^{\circ} \mathrm{C}\right)$ regime, high water content $(2 \mathrm{~h}$ boiling under water).

\subsection{Experimental mortars}

An experimental study was carried out to design a suitable mortar for restoration and conservation purposes with the durability against frost resistance as one of the central issues. Mortar test specimens were prepared with the different raw materials and compared with the Roman mortars from Sagalassos. For the production of quicklime, local limestone was taken from the Lycian nappes north of the city of Sagalassos. Lime was prepared by burning fragments $<4.75 \mathrm{~mm}$ of the limestone samples for $5 \mathrm{~h}$ at $900{ }^{\circ} \mathrm{C}$ with a heating and cooling rate of $5{ }^{\circ} \mathrm{C} / \mathrm{min}$. Slaking was done by immersing the $\mathrm{CaO}$ in a linen bag under water until no more reaction was observed. The aggregate/lime ratios used for the mixes were obtained from the ratios that were estimated from the results of the image analysis measurements on thin sections from the ancient mortars. The ratios used were (wt.\%): lime-crushed ceramics 65-35; lime-volcanics 45-55; lime-crushed ceramics-volcanics $40-40-20$. In the preparation of the test specimens, a certain mass of lime putty was chosen, enough to make two specimens of approximately $75 \times 38 \times 25 \mathrm{~mm}$. The mass of the crushed ceramics and/or the volcanic material to be used as aggregates is calculated from this value. Whenever limestone is used as an aggregate, the same weight of limestone fragments is added as the total weight of the crushed ceramics and the volcanic material. This ratio was derived from the original Roman mortar [2,9]. Masses are weighed in a measuring glass, so that the volume of the aggregates is obtained simultaneously. The bulk volume is measured without shaking or consolidating. In a porcelain dish, the aggregates and lime are gently but thoroughly mixed without further crushing and tap water is added until a consistent and workable mortar is obtained. The mix is brought into a metal mould and pressed to the correct shape. To prevent the mortar from sticking, the sides of the mould are prepared with oil. The test specimen is removed from the mould by gentle pressing and laid down to harden for 28 days on a metal plate with vent holes to allow carbonation from below. The test objects are turned regularly on all sides. The E-

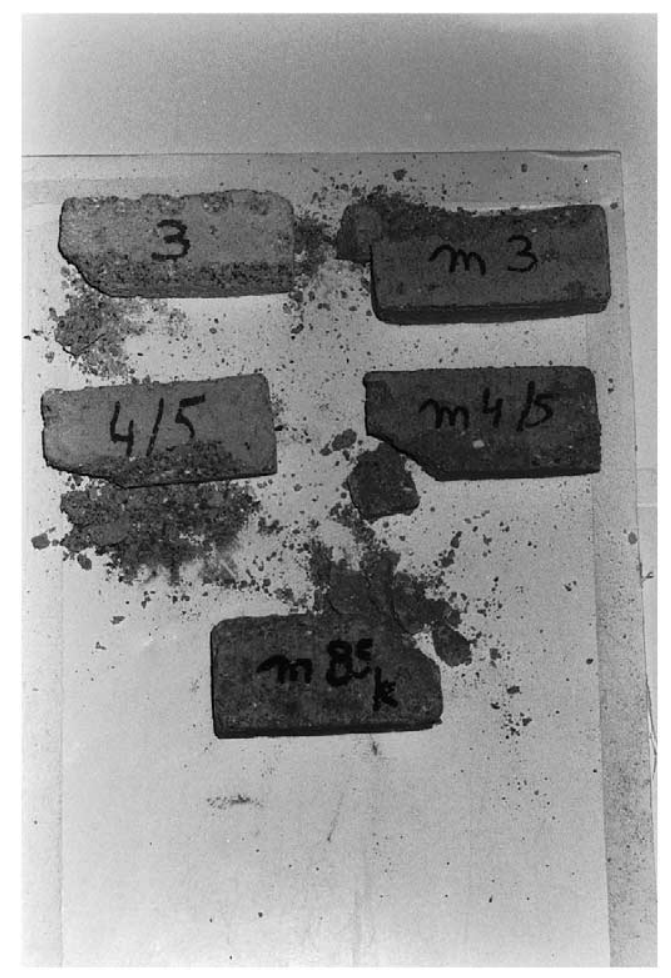

Fig. 5. Photograph of the test objects damaged and destroyed in the simulation of a high frost regime with a medium water content. 
moduli of the test specimens are measured throughout the carbonation of 28 days. After 28 days, the final E-modulus is measured and compared to that of the original Roman mortars. It needs to be stated that although the mortars will have obtained most of their strength through carbonation after 28 days, it is not a completed process and the carbonation of the mortar can go on for many years. The composition of these mortar test objects are listed in Table 1.

A measure of the mortar quality in this study was obtained by Grindosonic E-modulus measurement, which measures the resonance oscillation of a test object and compares it to that of a reference quartz crystal. This is not an exact measure for the absolute strength of a mortar, but offers an insight in the yield value of the sample. It may be used as a measure for the strength of the mortar object. For this test, the length of the test specimen should be about $6 \mathrm{~cm}$ and at least three times the height of this test specimen. The E-modulus method is further explained in Ref. [9]. The results for the measurements after 28 days (mean of two samples) are given in Table 1.

A freeze-thaw test was carried out to determine the frost resistance of the prepared mortar specimens. The principle of this unidirectional freezing test is described in DIN 52251, NEN 2879 and NBN B05-203 [12]. According to different climatic conditions, the following two parameters can be varied in the standardized testing procedure.

- The water content of the samples before the freezethaw test. We have chosen the medium water content

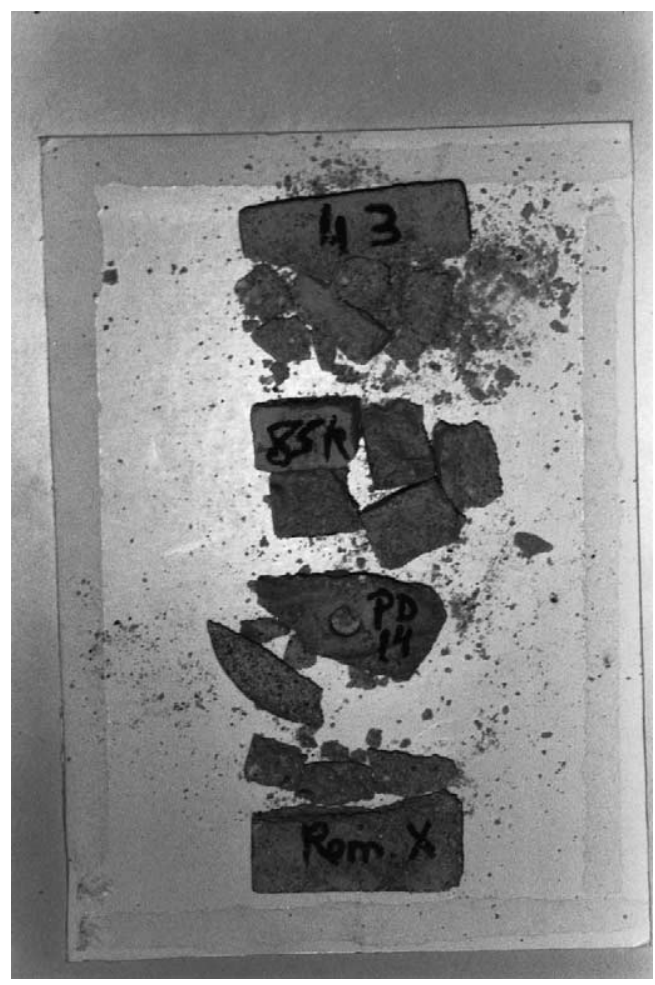

Fig. 6. Photograph of the test objects damaged and destroyed in the simulation of a high frost regime with a high water content.

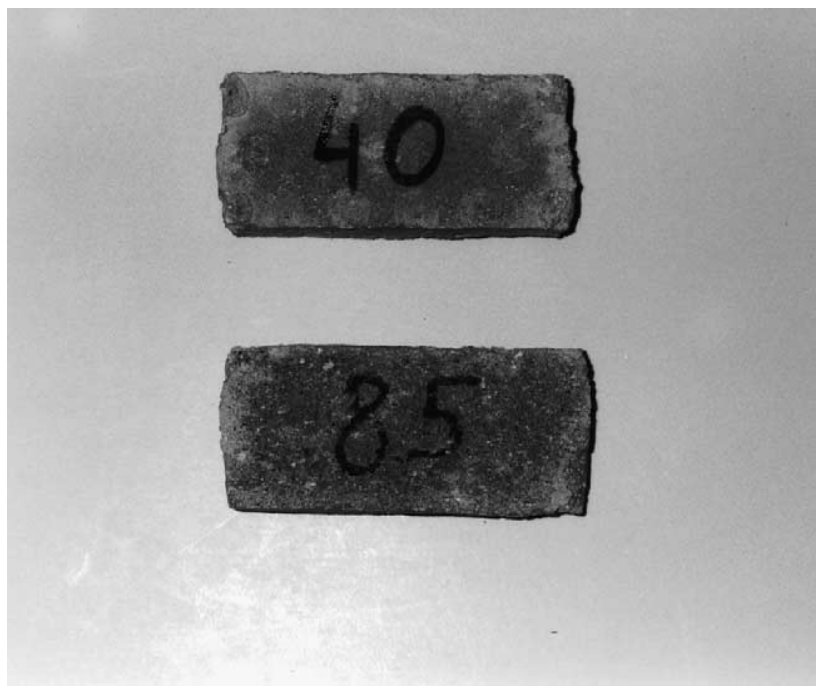

Fig. 7. Photograph of the test objects undamaged in the simulation of a high frost regime with a high water content.

whereby the samples were kept under water for $12 \mathrm{~h}$ and a high water content whereby the samples were boiled for $2 \mathrm{~h}$ under water.

- The frost regime. Freezing at $-5{ }^{\circ} \mathrm{C}$ is a low frost regime, at $-10{ }^{\circ} \mathrm{C}$ is a medium and at $-15{ }^{\circ} \mathrm{C}$ is a high frost regime. The samples are evaluated macroscopically for damage and their dynamic E-modulus is measured before and after the freezing-thawing cycles. In the first run of the climatic simulation tests, a high frost regime was combined with a medium water content for six freeze-thaw cycles, and in the second run, a high frost regime was combined with a high water content also for six freeze-thaw cycles.

The results of this test are summarised in Table 1. These results are also illustrated in Figs. 5-7. It is clear from these results that the mortars containing crushed ceramics are not frost resistant to a high frost regime. The mortars with only limestone aggregates are frost resistant to a certain extent but disintegrate in the high frost regime simulation. The mortar samples with only volcanic aggregates have a good frost resistance. Remarkable is the difference in frost resist-

Table 2

Grain size distribution of limestone aggregates used in test specimens (as defined by sieving)

\begin{tabular}{lll}
\hline Grain size & $\begin{array}{l}\text { Original Roman } \\
\text { aggregate }(\%)\end{array}$ & $\begin{array}{l}\text { Laboratory prepared } \\
\text { aggregate }(\%)\end{array}$ \\
\hline$>4.75 \mathrm{~mm}$ (rejected) & - & 53 \\
$<4.75 \mathrm{~mm}$ & 3.87 & 25.93 \\
$<4 \mathrm{~mm}$ & 30.58 & 39.34 \\
$<2 \mathrm{~mm}$ & 25.61 & 16.27 \\
$<1 \mathrm{~mm}$ & 14.09 & 7.69 \\
$<500 \mu \mathrm{m}$ & 11.42 & 3.96 \\
$<250 \mu \mathrm{m}$ & 8.82 & 2.42 \\
$<125 \mu \mathrm{m}$ & 5.64 & 3.30 \\
$<63 \mu \mathrm{m}$ & - & 1.09 \\
\hline
\end{tabular}




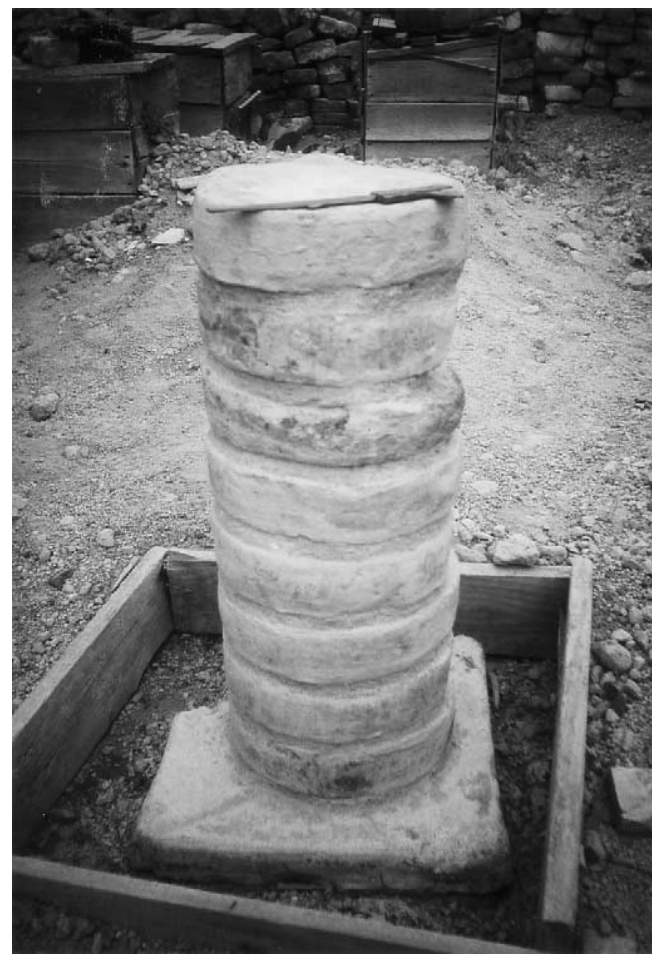

Fig. 8. Restoration mortar mix VO-1, undamaged after two winter seasons.

ance between the mortars with self-made limestone aggregates and aggregates recovered from original Roman specimens, where the latter are more frost resistant. It is clear that the grain size distribution of the limestone aggregates, given in Table 2 for both types of limestone aggregates used, plays an important role in providing the mortar mix with sufficient strength and frost resistance. The occurrence of Roman mortars with limestone aggregates in an excellent state at Sagalassos proves that the Roman engineers had optimised this feature of mortar production.

\section{Conclusions}

Mortars with only crushed ceramics (of building ceramics or common wares) as an aggregate were not suitable for building purposes, as they were too weak. Therefore, volcanic material (the same as for the building stones) was used from the region of Gölçük, just north of Sagalassos. However, mortars with only crushed ceramics were used as a watertight layer on building mortars, or to enhance the watertight aspects of a building mortar. The mortar strength can be enhanced by adding limestone to the mix. However, the grain size distribution of this aggregate is an important feature in this process. Also, the addition of crushed ceramics to a volcanic material/limestone mix enhances the mortar strength. However, very good (even the best) results for mortar strength can be obtained by using only limestone and volcanic material from Gölçük. Therefore, the use of additional crushed ceramics would be superfluous and thus economically unfavourable. Above all, the frost resistance of mortars with crushed ceramics as an aggregate, with or without volcanic material/limestone, is insufficient to resist the ruling climate at Sagalassos during winter. Mortars with volcanic aggregates, with or without limestone fragments, were used for most building purposes or on exterior surfaces. The mortars with the addition of crushed ceramics are suitable for circumstances where frost resistance has no interest, but where, for example, waterproofing is important. For further reconstruction purposes on the site, the mortar mix VO-1 (Table 1) was proposed, with raw materials readily available in the area. This restoration lime mortar was already applied in practice and has proven its suitability: Brick constructions restored with the VO-1 mortar mix successfully survived two winter seasons at Sagalassos (Fig. 8). The better freeze-thaw resistance of the mortars prepared with limestone and volcanic aggregates is probably due to an appropriate pore structure and sufficient mechanical strength. The better waterproofing behaviour of the mortars with the addition of fine crushed ceramic is believed to result from a denser pore structure of the mortar binder. The relation between pore structure, frost resistance and waterproofing is an ongoing topic of current research.

\section{Acknowledgments}

Dirk Steeno is greatly acknowledged for technical assistance. This research is supported by the Belgian Programme on Interuniversity Poles of Attraction initiated by the Belgian State, Prime Minister's Office, Science Policy Programming (IUAP IV/12). The text also presents results of a Concerted Action of the Flemish Government (GOA 97/2) and the Fund for Scientific Research-Flanders (Belgium) (FWO) (G.2145.94). M. Waelkens is L. BaertHofman's Professor in archaeology. Scientific responsibility is assumed by its authors.

\section{References}

[1] M. Waelkens, Sagalassos history and archaeology, in: M. Waelkens (Ed.), Sagalassos I, Acta Archaeologica. Lovaniensia Monographie, vol. 5, Universitaire Pers, Leuven, 1993, pp. 37-81.

[2] P. Degryse, Mineral resources and their use on the territory of Sagalassos (SW Turkey), Unpublished PhD thesis, Katholieke Universiteit Leuven, Leuven, 2001.

[3] M. Collepardi, Degradation and restoration of masonry walls of historic buildings, Mater. Struct. 23 (1990) 81-102.

[4] D. Michoinová, Lime based mortars for restoration of historical mortars especially under wall paintings, in: P.J.M. Bartos, C.J.W.P. Groot, J.J. Hughes (Eds.), Proceedings of the International RILEM Workshop 'Historic Mortars: Characteristics and Tests', RILEM, Paisley, 1999, pp. 287-295.

[5] Venice Charter, International Charter for the conservation and restoration of monuments and sites, Venice, 1964 (web site: 〈http://www. icomos.org/docs/venice_charter.html $\rangle$ ). 
[6] Nara Document, Nara Conference on Authenticity in Relation to the World Heritage Convention, Nara, 1994 (web site: 〈http://www.international.icomos.org/naradoc_eng.htm $\rangle$ ).

[7] D. Carrington, P. Swallow, Limes and lime mortars-part two, J. Archit. Conserv. 1 (1996) 7-22.

[8] R. Van Hees, Damage diagnosis and compatible repair mortars, RILEM, International Workshop on Historic Mortars: Characteristics and Tests, RILEM TC-167 COM, Paisley, 1999, pp. 27-35.

[9] W. Viaene, R. Ottenburgs, Ph. Muchez, M. Waelkens, The building stones of Sagalassos, in: M. Waelkens (Ed.), Sagalassos I, Acta Ar- chaeologica Lovaniensia Monographiae, vol. 5, Universitaire Pers, Leuven, 1993, pp. 85-92.

[10] K. Van Balen, Karbonatatie van kalkmortel en haar invloed op historische strukturen, Unpublished PhD thesis (in Dutch), Katholieke Universiteit Leuven, Leuven, 1991.

[11] K. Kraus, S. Wisser, D. Knöfel, Über das Löschen von Kalk vor der Mitte des 18, Jahrhunderts Literaturauswertung Laboversuche Arbeitsblätter Restauratoren 1 (1989) 206-221.

[12] L.J. Van der Klucht, Frost testing by uni-directional freezing, Ziegelind. Int. 2 (1989) 92-97. 